\title{
Editor's Comments
}

\section{This Month's Issue}

We have an eclectic mix of content in this issue of Information Technology and Libraries.

LITA President Cindi Trainor provides highlights of the recent LITA Forum in Louisville and planned LITA events for the upcoming ALA Midwinter Meeting in Philadelphia, including the LITA Town Meeting, the always-popular Top Tech Trends panel, and the Association's popular "networking event" on Sunday evening.

ITAL Editorial Board member Jerome Yavarkosky describes the significant benefits that immersive technologies can offer higher education. The advent of Massive Open Online Courses (MOOCs) would seem to present an ideal framework for the development of immersive library services to support learners who may otherwise lack access to quality library resources and services.

Responsive web design is the topic of a timely article by Hannah Gascho Rempel and Laurie M. Bridges, who examine what tasks library users actually carry out on a library mobile website and how this has informed Oregon State University Libraries' adoption of a responsive design approach for their website.

Piotr Praczyk, Javier Nogueras-Iso, and Salvatore Mele present a method for automatically extracting and processing graphical content from scholarly articles in PDF format in the field of high-energy physics. The method offers potential for enhancing access and search services and bridging the semantic gap between textual and graphical content.

Elizabeth Thorne Wallington describes the use of mapping and graphical information systems (GIS) to study the relationship between public library locations in the St. Louis area and the socioeconomic attributes of the populations they serve. The paper raises interesting questions about how libraries are geographically distributed and whether they truly provide universal and equal access.

Vadim Gureyev and Nikolai Mazov present a method for using bibliometric analysis of the publication output of two research institutes as a collection-development tool, to identify journals most important for researchers at the institutes.

Bob Gerrity (r.gerrity@uq.edu.au) is University Librarian, University of Queensland, Australia. 


\section{Editor's Comments}

\section{Bob Gerrity}

